\title{
Obesity survival paradox in pneumonia: a meta-analysis
}

Wei Nie ${ }^{1 \dagger}$, Yi Zhang ${ }^{2 \dagger}$, Sun Ha Jee ${ }^{3}$ Keum Ji Jung ${ }^{3}$, Bing Li $i^{{ }^{*}}$ and Qingyu Xiü ${ }^{1 *}$

\begin{abstract}
Background: It is unclear whether an 'obesity survival paradox' exists for pneumonia. Therefore, we conducted a meta-analysis to assess the associations between increased body mass index (BMI), pneumonia risk, and mortality risk.

Methods: Cohort studies were identified from the PubMed and Embase databases. Summary relative risks (RRs) with their corresponding 95\% confidence intervals (Cls) were calculated using a random effects model.

Results: Thirteen cohort studies on pneumonia risk $(n=1,536,623)$, and ten cohort studies on mortality $(n=1,375,482)$ were included. Overweight and obese individuals were significantly associated with an increased risk of pneumonia $\left(\mathrm{RR}=1.33,95 \% \mathrm{Cl} 1.04\right.$ to $\left.1.71, P=0.02, P^{2}=87 \%\right)$. In the dose-response analysis, the estimated summary RR of pneumonia per $5 \mathrm{~kg} / \mathrm{m}^{2}$ increase in BMI was $1.04(95 \% \mathrm{Cl} 1.01$ to $1.07, P=0.01, P=84 \%)$. Inversely, overweight and obese subjects were significantly associated with reduced risk of pneumonia mortality ( $\mathrm{RR}=0.83,95 \% \mathrm{Cl} 0.77$ to 0.91 , $\left.P<0.01, P^{2}=34 \%\right)$. The estimated summary RR of mortality per $5 \mathrm{~kg} / \mathrm{m}^{2}$ increase in BMI was $0.95(95 \% \mathrm{Cl} 0.93$ to 0.98 , $\left.P<0.01, P^{2}=77 \%\right)$.
\end{abstract}

Conclusions: This meta-analysis suggests that an 'obesity survival paradox' exists for pneumonia. Because this meta-analysis is based on observational studies, more studies are required to confirm the results.

Keywords: Body mass index, Obesity, Pneumonia, Dose-response relationship, Meta-analysis

\section{Background}

The prevalence of obesity has dramatically increased in the last two decades [1]. The diagnosis of obesity is often based on body mass index (BMI), calculated as weight in kilograms divided by height in meters squared $\left(\mathrm{kg} / \mathrm{m}^{2}\right)$. The ideal BMI is between 18.5 and 24.9. Being overweight is considered as having a BMI between 25 and 29.9, and being classified as obese falls into a BMI of 30.0 or greater [2]. Obesity is associated with an increased risk of cardiovascular disease and type 2 diabetes [3,4]. However, an inverse relationship between obesity and mortality has been described in patients with heart failure, coronary heart disease, and diabetes [5-7]. This phenomenon is known as the 'obesity survival paradox.'

Pneumonia is one of the most common infectious diseases; however, there is uncertainty about the association between obesity and pneumonia risk or pneumonia mortality [8-28]. For example, Baik et al. [9] suggested that obesity was directly associated with the development of community-acquired pneumonia (CAP). However, Phung et al. [19] did not find that obesity was significantly associated with pneumonia risk. Takata et al. [24] indicated that mortality risk was not different between obese pneumonia patients and normal weight patients. However, other studies reported that obese subjects with pneumonia had lower mortality compared to normal weight subjects [26-28]. Thus, whether the 'obesity survival paradox' exists in pneumonia is still unclear.

To date, no meta-analysis has shown whether an 'obesity survival paradox' exists for pneumonia. The aim of this meta-analysis was to investigate the relationships between elevated BMI, pneumonia risk, and mortality.

\section{Methods}

This meta-analysis was performed according to a predetermined protocol described in the following paragraphs, using standard systematic review techniques, as outlined by

\footnotetext{
*Correspondence: Ibxwzhao@gmail.com; xiu_qingyu@126.com

${ }^{\dagger}$ Equal contributors

'Department of Respiratory Medicine, Shanghai Changzheng Hospital, Second Military Medical University, 415 Fengyang Road, Shanghai 200003, China

Full list of author information is available at the end of the article
} 
the Meta-Analysis of Observational Studies in Epidemiology (MOOSE) criteria [29].

\section{Literature search}

A literature search was performed (WN and YZ) using the PubMed search engine, with the database being last accessed on 15 June 2013. The Embase database was also searched for relevant studies published up to June 2013. References from relevant articles were manually checked for further studies. The detailed search strategy is presented in the Additional file 1.

\section{Study selection}

Two reviewers (WN and YZ) independently screened the abstracts of papers identified by the literature search, retrieved potentially relevant studies and determined study eligibility. Studies were included if: (1) the study design was a prospective or retrospective cohort study; (2) the exposure of interest was BMI; (3) they reported adjusted relative risks (RRs), hazard ratios (HRs) or odds ratios (ORs) with corresponding 95\% confidence intervals (CIs), or provided a $\mathrm{RR} / \mathrm{HR} / \mathrm{OR}$ with corresponding 95\% CI per unit increment in BMI; and (4) the outcome was pneumonia incidence or mortality. If the same cohort was used in more than one publication, we included the publication that reported the results in greater detail or, if similar, the one with the largest number of cases. Data published only in abstract form were excluded. Case reports, review articles and commentary articles were also excluded. Studies with pediatric participants or pregnant populations were not included.

\section{Data collection and methodological quality assessment}

From each study, two reviewers (WN and YZ) independently extracted the first author, publication year, study design, location where the study was performed, number of cases and cohort size, gender and age of study participants, follow-up duration, method for assessing height and weight, ascertainment of pneumonia, type of pneumonia, BMI category, adjusted RR/HR/OR and the corresponding 95\% CI, and covariates controlled for multivariable analysis. The authors of the relevant studies were contacted by Email if more information was needed.

Two independent reviewers (WN and YZ) completed the quality assessment. The Newcastle-Ottawa Scale (NOS) was used to evaluate the methodological quality, which scored studies by the selection of the study groups, the comparability of the groups and the ascertainment of the outcome of interest [30]. Discrepancies were resolved by consensus and discussion. The detailed criteria of the methodological quality assessment are in Additional file 2.

\section{Statistical analysis}

For pneumonia risk and pneumonia mortality risk, we calculated summary RRs and 95\% CIs for overweight and obesity versus normal weight. The random effects model was utilized. HRs and ORs were regarded as equivalent to RRs in cohort studies. If a study reported results specifically for men and women, respectively, we combined the sex-specific RR estimates using a fixedeffects model before combining with other studies.

In dose-response analysis, we calculated the RR per 5 -unit increase in the BMI levels for each study. The average of the natural logarithm of the RRs was estimated and the RR from each study was weighted by the inverse of its variance. A two-tailed $P<0.05$ was considered statistically significant. We also combined the sex-specific estimates using a fixed-effects model to generate an estimate for both genders combined. The method described by Greenland and Longnecker [31] was used for the doseresponse analysis and study-specific slopes (linear trends) and 95\% CIs were computed from the natural logs of the RRs and CIs across categories of BMI. This method requires the distribution of case and person-years and the median level of BMI in each category to the corresponding RR for each study (the RRs with estimates for at least three quantitative exposure categories are known). The midpoint between the upper and lower boundary for each BMI category was assigned to the corresponding RR estimate. For studies with an open-ended highest or lowest BMI category, we assumed that the amplitude was the same as the closest adjacent category. Random effects models were used to pool the respective results. The dose-response results in the forest plot were presented for a $5 \mathrm{~kg} / \mathrm{m}^{2} \mathrm{BMI}$ increment.

Nonlinear dose-response curves were plotted using restricted cubic splines for each study, using knots fixed at percentiles $10 \%, 50 \%$ and $90 \%$ through the distribution; then these were combined using multivariate meta-analysis [32-34].

Statistical heterogeneity among studies was evaluated using the Q and $I^{2}$ statistics. For the $I^{2}$ metric, we considered low, moderate and high $I^{2}$ values to be $25 \%, 50 \%$ and $75 \%$, respectively. We examined the role of several potential sources of heterogeneity by subgroup analyses according to study design, gender, ascertainment of case, pneumonia type, assessment of anthropometry, and duration of follow-up. Meta-regression was also performed to find the sources of heterogeneity. Sensitivity analysis was conducted by excluding one study at a time to explore whether the results were driven by one large study or by a study with an extreme result. Potential small study effects, such as publication bias, were investigated with funnel plots.

All statistical analyses were performed with the Stata software (version 12.0, Stata Corporation, College Station, Texas). A threshold of $P<0.1$ was used to decide whether heterogeneity was present. In other cases, $P$ values were two sided with a significance level of 0.05 . 


\section{Results}

\section{Literature search}

The process of identifying relevant studies is shown in Figure 1. The initial search produced 1,035 studies from the PubMed and Embase databases. After exclusion of duplicates and irrelevant studies, 115 potentially eligible studies were selected. After detailed evaluations, 21 studies were selected for final meta-analysis [8-28]. A manual search of reference lists from these studies did not yield any new eligible study. Several studies investigated the association between BMI and mortality. We contacted these authors to get additional data on pneumonia mortality. Dr. Sun Ha Jee and colleague shared their data [35]. Finally, 22 studies were included in this meta-analysis [8-28,35].

\section{Study characteristics}

Twelve cohort studies $(n=1,536,623)$ investigated the association between BMI and pneumonia risk [8-19], and ten studies $(\mathrm{n}=1,375,482)$ assessed the association between BMI and pneumonia mortality [20-28,35]. There were seven retrospective cohort studies $[11,15-18,25,26]$ and fifteen prospective cohort studies [8-10,12-14,19-24,27,28,35]. The durations of follow-up varied from 1 year to 15.8 years. Sixteen studies collected measured BMI [8,10-15,19,20,23-28,35]; three studies collected self-reported data $[9,17,21]$. The characteristics of each study are presented in Table 1 . The methodological quality assessment is provided in Additional file 2. The Preferred Reporting Items for Systematic Reviews and Meta-Analyses (PRISMA) checklist for meta-analysis is provided in Additional file 3.

\section{Quantitative data synthesis}

Pneumonia risk (overweight and obesity versus normal weight) Compared with normal weight individuals, overweight and obese individuals were associated with a significantly increased risk of pneumonia $(\mathrm{RR}=1.33,95 \%$ CI 1.04 to $\left.1.71, P=0.02, I^{2}=87 \%\right)$. A small-study effect was demonstrated using a funnel plot [see Additional file 4]. Ten studies reported RRs for categorized BMI levels [9-17,19]. Thus, we included these studies for the dose-response analysis. The summary RR was 1.04 (95\% CI 1.01 to $1.07, P=0.01$, $I^{2}=84 \%$; Figure 2). A potentially nonlinear dose-response relationship was not detected $(P>0.05$; Figure 3$)$. We found evidence of a small-study effect as assessed by funnel plot [see Additional file 5].

We conducted a sensitivity analysis by omitting one study at a time and calculating the pooled RRs for the remainder of the studies. This sensitivity analysis showed that the results were not changed (data not shown). The

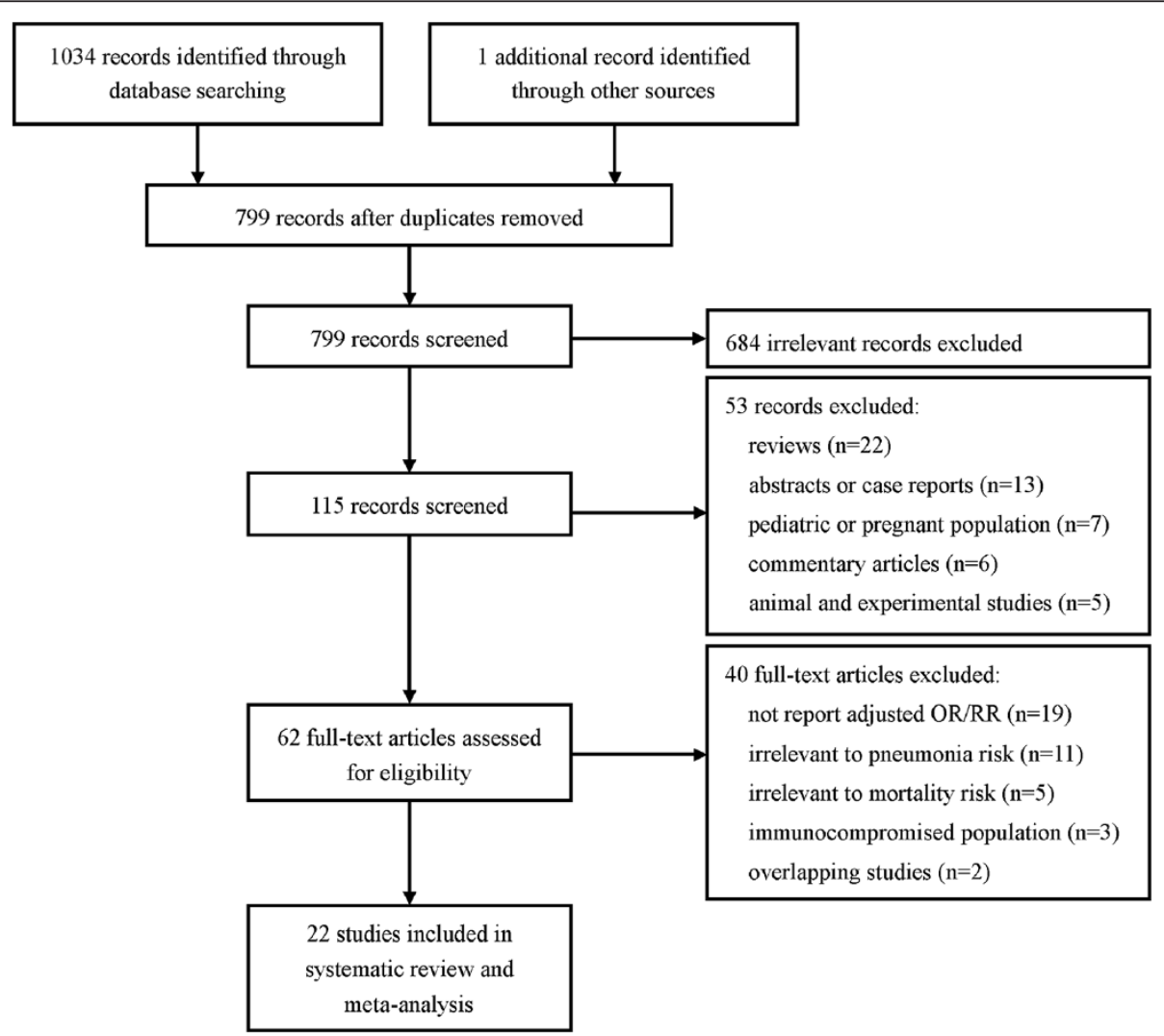

Figure 1 Flow of study identification, inclusion and exclusion. 
Table 1 Characteristics of included cohort studies

Author Study Year Location Gender Age (y)

Years of
follow-up
(y)

\begin{tabular}{l}
$\begin{array}{l}\text { Assessment Sample } \\
\text { of weight } \\
\text { and height }\end{array}$ \\
\hline
\end{tabular}

Cases

No. of Type BMI category

Adjustment for covariates

design

and height

ascertainment cases

$\left(\mathrm{kg} / \mathrm{m}^{2}\right)$

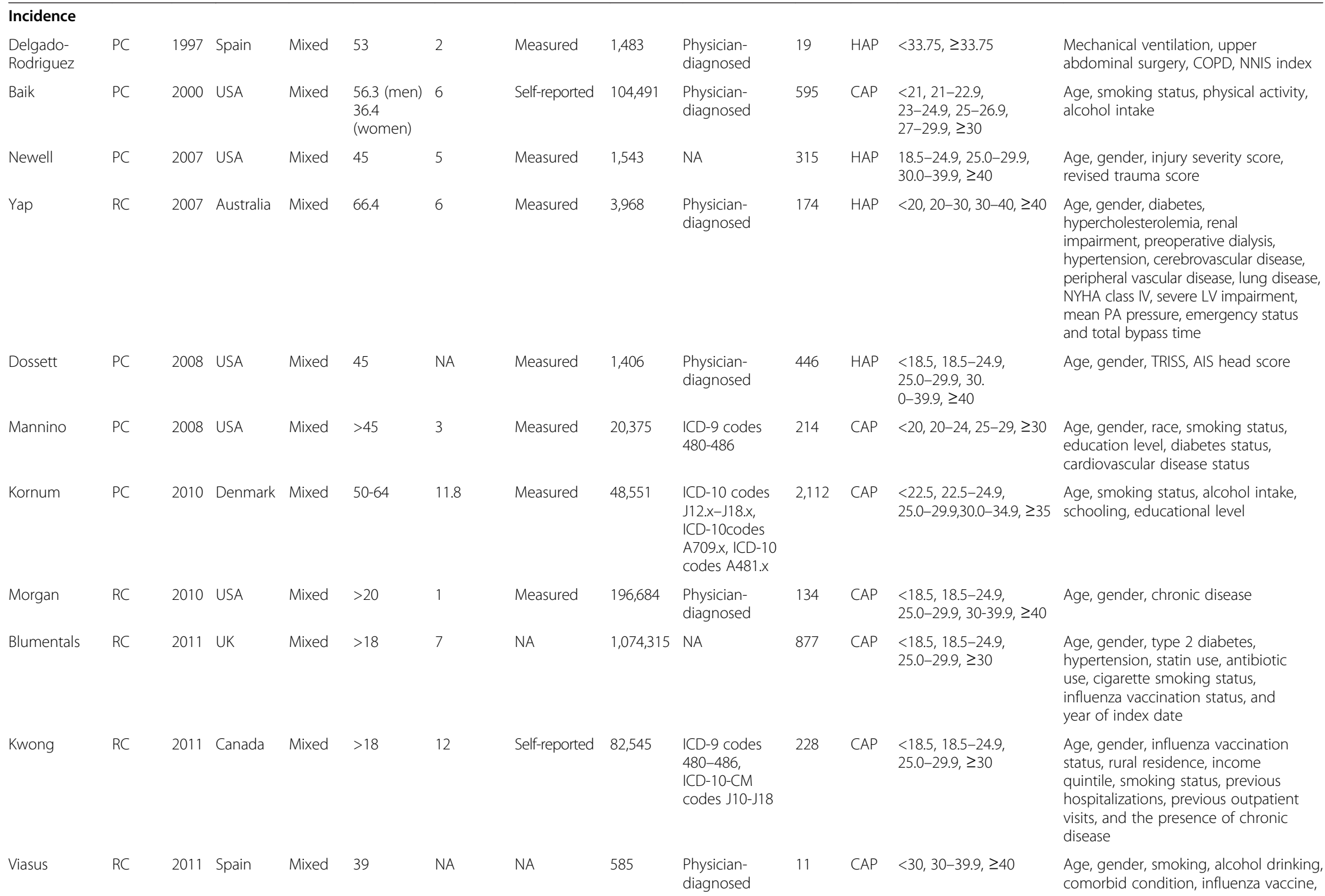


Table 1 Characteristics of included cohort studies (Continued)

\begin{tabular}{|c|c|c|c|c|c|c|c|c|c|c|c|c|c|}
\hline \multicolumn{14}{|l|}{ Mortality } \\
\hline LaCROIX & $P C$ & 1989 & USA & Mixed & 65.8 & 12 & Measured & 5474 & $\begin{array}{l}\text { ICD-9 codes } \\
480-486\end{array}$ & 76 & CAP & $\begin{array}{l}\text { Lowest quartile, Second } \\
\text { quartile,Third quartile, } \\
\text { Highest quartile }\end{array}$ & Age \\
\hline Salive & $P C$ & 1993 & USA & Mixed & 74 & 6 & Self-reported & 10,269 & $\begin{array}{l}\text { ICD-9 codes } \\
480-486\end{array}$ & 403 & CAP & $\begin{array}{l}\text { Lowest quartile, Second } \\
\text { quartile,Third quartile, } \\
\text { Highest quartile }\end{array}$ & $\begin{array}{l}\text { Age, race, education, co-morbidities, } \\
\text { smoking, peak expiratory flow, } \\
\text { emphysema, exercise }\end{array}$ \\
\hline Lange & $P C$ & 1995 & Denmark & Mixed & $30-70$ & 12 & NA & 13,423 & $\begin{array}{l}\text { ICD- } 8 \text { codes } \\
480-486\end{array}$ & 260 & CAP & $<20,20-29, \geq 30$ & $\begin{array}{l}\text { Age, predicted forced expiratory } \\
\text { volume in one second }\end{array}$ \\
\hline Jee & $P C$ & 2006 & Korea & Mixed & 46 & 15 & Measured & $1,213,829$ & ICD-10 & 962 & CAP & $\begin{array}{l}<18.5,18.5-19.9 \\
20.0-21.4,21.5-22.9, \\
23.0-24.9,25.0-26.4 \\
26.5-27.9,28.0-29.9 \\
30.0-31.9\end{array}$ & $\begin{array}{l}\text { Age, smoking status, alcohol intake, } \\
\text { physical exercise, physical activity }\end{array}$ \\
\hline Inoue & $P C$ & 2007 & Japan & Mixed & 57.6 & 13 & Measured & 110,792 & $\begin{array}{l}\text { ICD-9 codes } \\
480-486 \text { ICD-10 } \\
\text { codes } J 12-J 18\end{array}$ & 1,082 & CAP & $\begin{array}{l}10.0-17.9,18.0-22.9 \\
23.0-24.9,25.0-32.9\end{array}$ & Age, diabetes mellitus \\
\hline Takata & $P C$ & 2007 & Japan & Mixed & 80 & 4 & Measured & 697 & ICD-10 & 19 & CAP & $<18.5,18.5-24.9, \geq 25$ & $\begin{array}{l}\text { Gender, tobacco use, alcohol use, } \\
\text { weight loss, current outpatient, systolic } \\
\text { blood pressure, physical activity, } \\
\text { functional status, marital status, and } \\
\text { levels of total serum cholesterol } \\
\text { and glucose }\end{array}$ \\
\hline $\begin{array}{l}\text { Corrales- } \\
\text { Medina }\end{array}$ & $\mathrm{RC}$ & 2011 & USA & Mixed & 65.5 & 7 & Measured & 266 & $\begin{array}{l}\text { Physician- } \\
\text { diagnosed }\end{array}$ & 31 & CAP & $\begin{array}{l}<18.5,18.5-24.9 \\
25.0-29.9,>30\end{array}$ & Age, race, cancer, CURB-65 \\
\hline King & $\mathrm{RC}$ & 2012 & USA & Mixed & 67.5 & 7 & Measured & 18,746 & $\begin{array}{l}\text { ICD-9 codes } \\
480-487\end{array}$ & 3,340 & CAP & $\begin{array}{l}<18.5,18.5-24.9 \\
25.0-29.9,30-39.9,>40\end{array}$ & $\begin{array}{l}\text { Age, gender, marital status, race, count } \\
\text { of current medications, medical and } \\
\text { psychiatric comorbid conditions, alcohol } \\
\text { abuse, tobacco use, and drug abuse }\end{array}$ \\
\hline Kahlon & PC & 2012 & Canada & Mixed & 68 & 2 & Measured & 907 & $\begin{array}{l}\text { Physician- } \\
\text { diagnosed }\end{array}$ & 79 & CAP & $\begin{array}{l}<18.5,18.5-24.9 \\
25.0-29.9,>30\end{array}$ & $\begin{array}{l}\text { Age, functional status, prior } \\
\text { pneumococcal vaccination, chest } \\
\text { radiograph confirmation, PSI }\end{array}$ \\
\hline Singanayagam & $P C$ & 2013 & UK & Mixed & $50-78$ & NA & Measured & 1,079 & $\begin{array}{l}\text { Physician- } \\
\text { diagnosed }\end{array}$ & 103 & CAP & $\begin{array}{l}<18.5,18.5-24.9 \\
25.0-29.9,30.0-34.9\end{array}$ & $\begin{array}{l}\text { Age, gender, co-morbidities, current } \\
\text { smoking, functional status, nursing } \\
\text { home residence, PSI }\end{array}$ \\
\hline
\end{tabular}

AIS, abbreviated injury score; BMI, body mass index; CAP, community-acquired pneumonia; COPD, chronic obstructive pulmonary diseases, CURB-65, confusion, urea $>7$ mmol/L, respiratory rate $\geq 30$ breaths/minute, low blood pressure and age $\geq 65$ years; F, female; HAP, hospital-acquired pneumonia; ICD, International Classification of Diseases; LV, left ventricle; M, male; NA, not available; NNIS, National Nosocomial Infection Surveillance; NYHA, New York Heart Association; PC, prospective cohort; PSI, Pneumonia Severity Index; RC, retrospective cohort; TRISS, trauma-related injury severity score. 


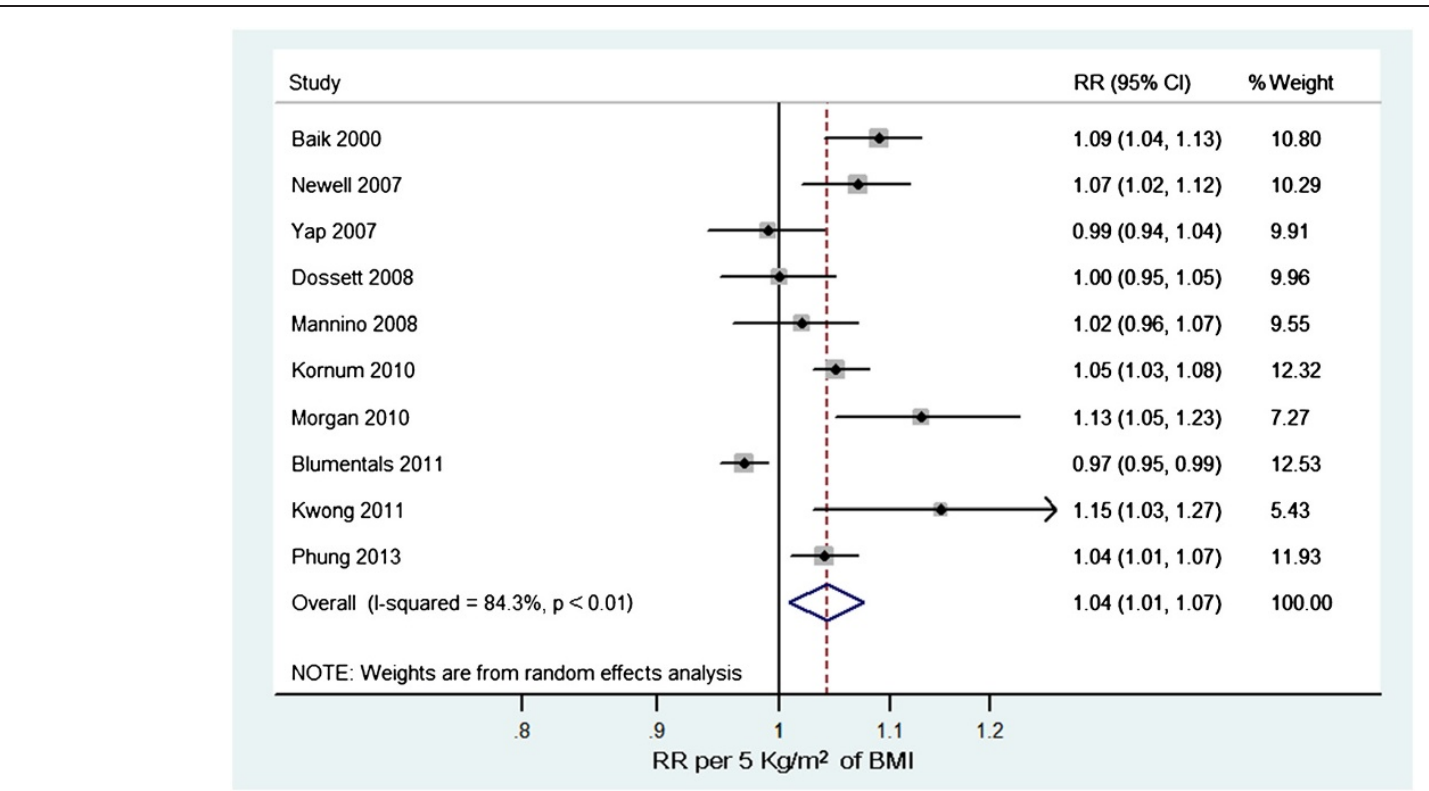

Figure 2 Relative risks of pneumonia risk per 5 kg/m2 increase in body mass index. Cl: indicates confidence interval; and RR: risk ratio.

potential sources of heterogeneity were explored by stratifying analyses. Studies comparing overweight and obese subjects with normal weight subjects, and studies assessing dose-response associations were explored, respectively. The positive relationship between BMI and risk of pneumonia was significant in subgroups by ascertainment of case and assessment of weight and height [see Additional file 6]. However, in subgroups of retrospective cohort studies, male population, female population, hospital-acquired pneumonia, and longer follow-up duration, the positive relationships were not statistically significant [see Additional file 6]. A meta-regression found that assessment of weight and height might be the source of the high heterogeneity.

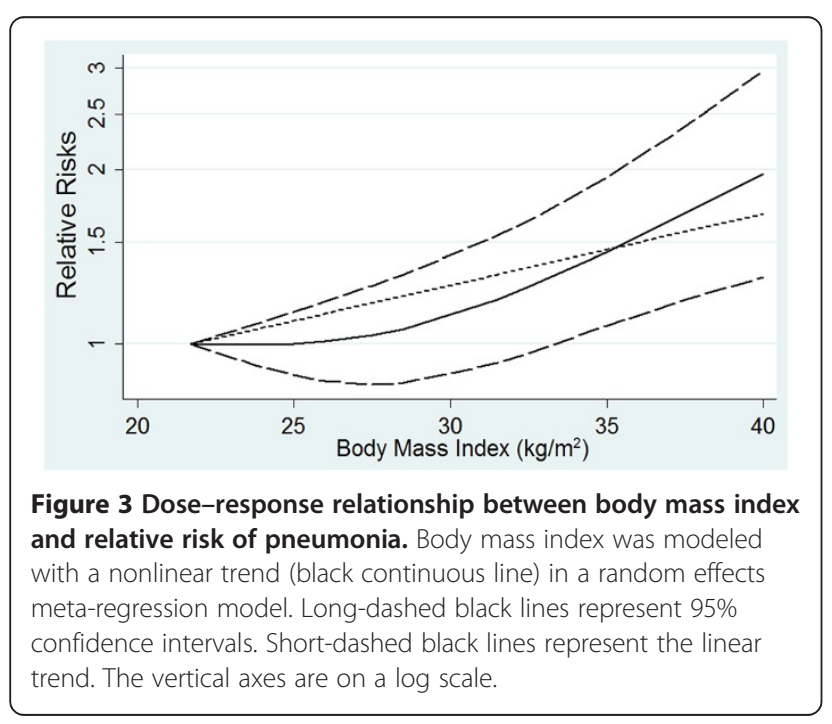

\section{Pneumonia mortality risk (overweight and obese versus} normal weight)

Overweight and obese individuals were associated with decreased mortality risk $(\mathrm{RR}=0.83,95 \% \mathrm{CI} 0.77$ to 0.91 , $\left.P<0.01, I^{2}=34 \%\right)$. A small-study effect was revealed by the funnel plot [see Additional file 7].

Six cohort studies were identified in the dose-response analysis [23,25-28,35]. The summary RR was 0.95 (95\% CI 0.93 to $0.98, P<0.01, I^{2}=77 \%$; Figure 4$)$. There was no evidence of a nonlinear relationship with BMI $(P=0.44$; Figure 5). The shape of the funnel plot was asymmetrical, suggesting that there was a small-study effect [see Additional file 8].

In sensitivity analyses, no result was significantly altered when excluding studies one by one (data not shown). Stratified analyses were defined by study design, gender, assessment of weight and height, and follow-up duration. Studies comparing overweight and obese subjects with normal weight subjects, and studies assessing dose-response associations were explored, respectively. The inverse relationship between BMI and risk of mortality was significant in subgroups that were defined by ascertainment of case and study design. However, in the female subgroup or studies with shorter follow-up duration, the inverse relationship was not statistically significant [see Additional file 9]. Study design was found to be the major source of heterogeneity by meta-regression.

\section{Discussion}

In this meta-analysis, we showed that an 'obesity survival paradox' might exist for pneumonia. On the one hand, there was a positive association of obesity with pneumonia 


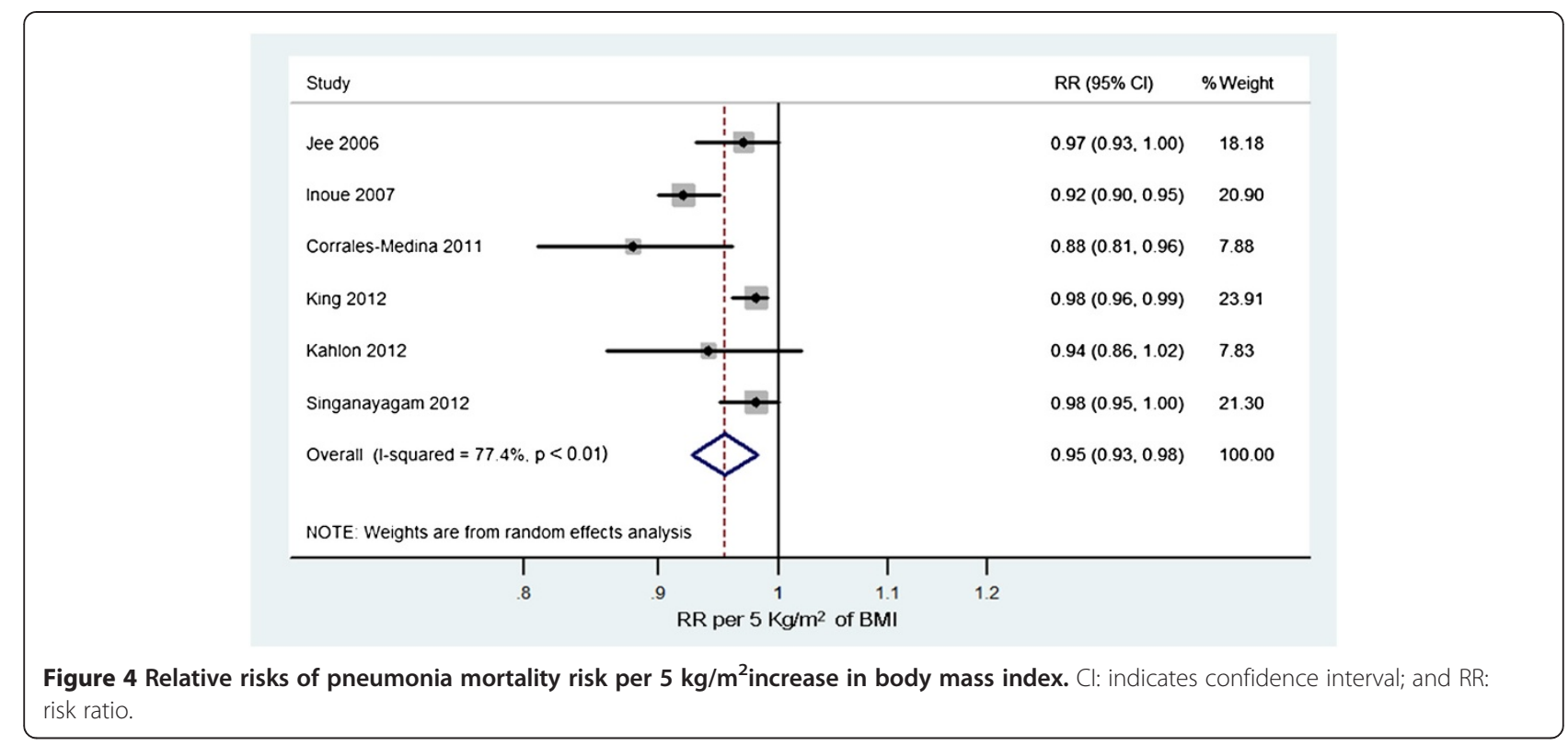

risk. On the other hand, pneumonia mortality was lower for patients with high BMI compared to normal BMI.

In a recent meta-analysis, Phung and coworkers found a J-shaped relationship between BMI and risk of CAP and a U-shaped relationship between BMI and risk of influenza-related pneumonia [36]. Our results were partly similar to this previous report. In the current meta-analysis, we only investigated the association between higher BMI and pneumonia risk, but did not assess the association between subnormal BMI and pneumonia risk. Thus, the shape of our dose-response relationship deviated from J-shaped or U-shaped.

There were several potential explanations for why obese individuals may have higher risk of pneumonia. First, obesity is often accompanied by co-morbid conditions, such as gastroesophageal reflux disease [37]. When reflux

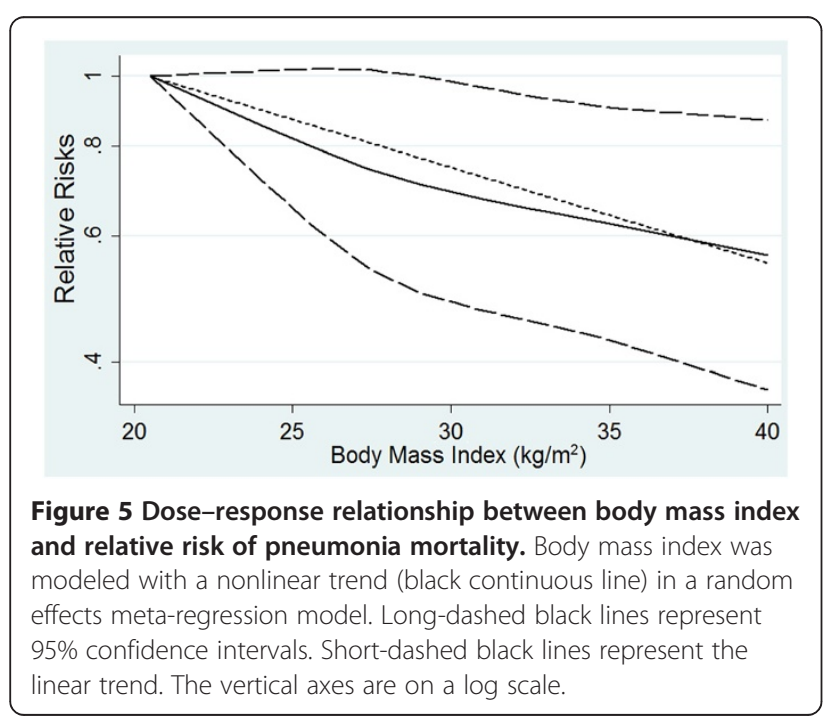

of gastric fluid occurs, the fluid can be aspirated into the respiratory tract resulting in pneumonia [37]. Second, obesity has been shown to be an independent predictor of diabetes and asthma. These two diseases are also important risk factors for pneumonia [38,39]. Third, a recent study reported that a higher $\mathrm{BMI}$ led to lower $25(\mathrm{OH}) \mathrm{D}_{3}$ levels [40]. More recently, Aregbesola and colleagues found that subjects with a lower serum $25(\mathrm{OH}) \mathrm{D}_{3}$ concentration had a higher risk of pneumonia [41]. Fourth, leptin $(o b / o b)$ and leptin receptor $(d b / d b)$ deficient mice showed severe immune abnormalities and greater susceptibility to viral and bacterial infection [42]. Individuals with this leptin defect also exhibited greater susceptibility to respiratory infections [43]. Therefore, leptin plays an important role in the human immune response to infectious disease. Although there were elevated leptin levels in obese subjects, leptin resistance often coexisted with these persons [44]. Taken together, these results suggest that individuals with high BMI might have an increased risk of pneumonia compared to subjects with normal BMI.

This present meta-analysis suggested a survival advantage for obese patients with pneumonia. A study by LaCroix et al. showed that the risk of pneumonia mortality was 2.6 times higher in men of the lowest BMI quartile compared to the highest quartile [20]. Another study by Salive et al. indicated that the highest two quartiles of BMI had a significantly reduced risk of mortality compared with the lowest quartile [21]. We propose three explanations for the inverse relationship between obesity and the risk of pneumonia mortality. First, obese individuals have a higher risk of developing coronary heart disease, type II diabetes, and heart failure [45]. Thus, obese patients with pneumonia may receive optimal medical treatment or aggressive treatment. This may lead to a reduction in mortality. Second, 
tumor necrosis factor-alpha (TNF- $\alpha$ ) is a potential proinflammatory cytokine that plays a critical role in inflammatory and immune responses. Puren et al. [46] indicated that the plasma level of TNF- $\alpha$ is a marker of pneumonia severity. Adipose tissue is known to produce soluble TNF$\alpha$ receptors [47]. Additionally, recent studies showed that obese patients with pneumonia had lower pneumonia severity index scores and plasma levels of $\mathrm{C}$-reactive protein $[27,28]$. Third, as with other diseases, patients with pneumonia who are at a normal weight may not have enough metabolic reserve to counteract the increased catabolic stress. These patients may be particularly vulnerable to the adverse pathophysiologic consequences of a limited metabolic reserve.

There are several limitations of the current study. First, a meta-analysis of observational studies inherits the limitation of the original studies. Although most studies adjusted for potential confounders, such as age, gender, smoking and underlying diseases, the possibility of residual confounding cannot be ruled out. Because this meta-analysis investigated only BMI, we cannot exclude the possibility that the observed associations may be confounded by other lifestyle factors, such as lower physical activity or dietary factors. Second, the number of available studies that were included in this meta-analysis was moderate. Therefore, the results could be influenced by some factors, such as random error. Third, most of the studies used International Classification of Diseases (ICD)-9 or ICD-10 codes to classify pneumonia. van de Garde and coworkers suggested that ICD-9 codes showed modest sensitivity for detecting CAP, leaving at least one quarter of pneumonia cases undetected [48]. Fourth, statistical heterogeneity was detected when quantitative pooling was performed. In addition, small-study effects were detected in this study. Thus, caution with interpretation of the results is necessary, and these results should be confirmed by future studies.

\section{Conclusions}

This meta-analysis suggests that obese individuals may be at higher risk for pneumonia, but they might have a lower mortality risk. Additional prospective studies with adjustment for more confounding factors are warranted before a conclusion can be drawn.

\section{Additional files}

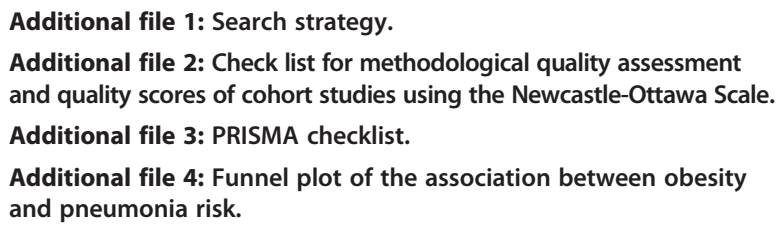

Additional file 5: Funnel plot of the association between obesity and pneumonia risk in dose-response analysis.
Additional file 6: Subgroup analyses of pneumonia risk, overweight and obesity versus normal weight and dose-response analyses, respectively.

Additional file 7: Funnel plot of the association between obesity and pneumonia mortality risk.

Additional file 8: Funnel plot of the association between obesity and pneumonia mortality risk in dose-response analysis.

Additional file 9: Subgroup analyses of pneumonia mortality risk, overweight and obesity versus normal weight and dose-response analyses, respectively.

\section{Abbreviations}

BMI: body mass index; CAP: community-acquired pneumonia; $\mathrm{Cl}$ : confidence interval; HAP: hospital-acquired pneumonia; ICD: International Classification of Diseases; NOS: Newcastle-Ottawa Scale; RR: risk ratio; TNF-a: tumor necrosis factor-alpha.

\section{Competing interests}

The authors declare that they have no competing interests.

\section{Authors' contributions}

WN searched the papers, created tables, and wrote the manuscript. YZ searched the papers, created tables, and wrote the manuscript. SHJ analyzed and provided data. KJ analyzed and provided data. BL reviewed the study proposal and contributed to the manuscript writing. QX reviewed the study proposal and contributed to the manuscript writing. All authors read and approved the final manuscript.

\section{Acknowledgements}

This study was supported by grants No. 81170025 from National Natural Science Foundation of China and projects of "Major New Drugs Innovation and Development" from the National Ministry of Science and Technology (No. 2011ZX09302-003-001). The funders had no role in study design, data collection and analysis, decision to publish, or preparation of the manuscript.

\section{Author details}

${ }^{1}$ Department of Respiratory Medicine, Shanghai Changzheng Hospital, Second Military Medical University, 415 Fengyang Road, Shanghai 200003, China. ${ }^{2}$ Department of Clinical Nutrition, The 452nd Hospital of PLA, Chengdu 610000, Sichuan, China. ${ }^{3}$ Department of Epidemiology and Health Promotion, Graduate School of Public Health, Yonsei University, Seoul 120-749, Korea.

Received: 26 November 2013 Accepted: 13 March 2014

Published: 10 April 2014

\section{References}

1. Baskin ML, Ard J, Franklin F, Allison DB: Prevalence of obesity in the United States. Obes Rev 2005, 6:5-7.

2. Berrington de Gonzalez A, Hartge P, Cerhan JR, Flint AJ, Hannan L, Maclnnis RJ, Moore SC, Tobias GS, Anton-Culver H, Freeman LB, Beeson WL, Clipp SL, English DR, Folsom AR, Freedman DM, Giles G, Hakansson N, Henderson KD, Hoffman-Bolton J, Hoppin JA, Koenig KL, Lee IM, Linet MS, Park Y, Pocobelli G, Schatzkin A, Sesso HD, Weiderpass E, Willcox BJ, Wolk A, et al: Body-mass index and mortality among 1.46 million white adults. N Engl J Med 2010, 363:2211-2219.

3. Lavie CJ, Milani RV, Ventura HO: Obesity and cardiovascular disease: risk factor, paradox, and impact of weight loss. J Am Coll Cardiol 2009, 53:1925-1932

4. Narayan KM, Boyle JP, Thompson TJ, Gregg EW, Williamson DF: Effect of BMI on lifetime risk for diabetes in the U.S. Diabetes Care 2007, 30:1562-1566.

5. Lavie CJ, Alpert MA, Arena R, Mehra MR, Milani RV: Impact of obesity and the obesity paradox on prevalence and prognosis in heart failure. JACC Heart Failure 2013, 1:93-102.

6. De Schutter A, Lavie CJ, Milani RV: The impact of obesity on risk factors and prevalence and prognosis of coronary heart disease-the obesity paradox. Prog Cardiovasc Dis 2014, 56:401-408.

7. Carnethon MR, De Chavez PJ, Biggs ML, Lewis CE, Pankow JS, Bertoni AG, Golden SH, Liu K, Mukamal KJ, Campbell-Jenkins B, Dyer AR: Association of 
weight status with mortality in adults with incident diabetes. JAMA 2012, 308:581-590.

8. Delgado-Rodríguez M, Medina-Cuadros M, Martínez-Gallego G, Sillero-Arenas M: Usefulness of intrinsic surgical wound infection risk indices as predictors of postoperative pneumonia risk. J Hosp Infect 1997, 35:269-276.

9. Baik I, Curhan GC, Rimm EB, Bendich A, Willett WC, Fawzi WW: A prospective study of age and lifestyle factors in relation to community-acquired pneumonia in US men and women. Arch Intern Med 2000, 160:3082-3088.

10. Newell MA, Bard MR, Goettler CE, Toschlog EA, Schenarts PJ, Sagraves SG, Holbert D, Pories WJ, Rotondo MF: Body mass index and outcomes in critically injured blunt trauma patients: weighing the impact. J Am Coll Surg 2007, 204:1056-1061.

11. Yap CH, Zimmet A, Mohajeri M, Yii M: Effect of obesity on early morbidity and mortality following cardiac surgery. Heart Lung Circ 2007, 16:31-36.

12. Dossett LA, Heffernan D, Lightfoot M, Collier B, Diaz JJ, Sawyer RG, May AK: Obesity and pulmonary complications in critically injured adults. Chest 2008, 134:974-980.

13. Mannino DM, Davis KJ, Kiri VA: Chronic obstructive pulmonary disease and hospitalizations for pneumonia in a US cohort. Respir Med 2009, 103:224-229.

14. Kornum JB, Nørgaard M, Dethlefsen C, Due KM, Thomsen RW, Tjønneland A Sørensen HT, Overvad K: Obesity and risk of subsequent hospitalisation with pneumonia. Eur Respir J 2010, 36:1330-1336.

15. Morgan OW, Bramley A, Fowlkes A, Freedman DS, Taylor TH, Gargiullo P, Belay B, Jain S, Cox C, Kamimoto L, Fiore A, Finelli L, Olsen SJ, Fry AM: Morbid obesity as a risk factor for hospitalization and death due to 2009 pandemic influenza A(H1N1) disease. PLoS One 2010, 5:e9694.

16. Blumentals WA, Nevitt A, Peng MM, Toovey S: Body mass index and the incidence of influenza-associated pneumonia in a UK primary care cohort. Influenza Other Respir Viruses 2012, 6:28-36.

17. Kwong JC, Campitelli MA, Rosella LC: Obesity and respiratory hospitalizations during influenza seasons in Ontario, Canada: a cohort study. Clin Infect Dis 2011, 53:413-421

18. Viasus D, Paño-Pardo JR, Pachón J, Campins A, López-Medrano F, Villoslada A, Fariñas MC, Moreno A, Rodríguez-Baño J, Oteo JA, Martínez-Montauti J, Torre-Cisneros J, Segura F, Gudiol F, Carratalà J, Novel Influenza A (H1N1) Study Group of the Spanish Network for Research in Infectious Diseases (REIPI): Factors associated with severe disease in hospitalized adults with pandemic (H1N1) 2009 in Spain. Clin Microbiol Infect 2011, 17:738-746.

19. Phung D, Wang Z: Risk of pneumonia in relation to body mass index in Australian Aboriginal people. Epidemiol Infect 2013, 141:2497-2502.

20. LaCroix AZ, Lipson S, Miles TP, White L: Prospective study of pneumonia hospitalizations and mortality of U.S. older people: the role of chronic conditions, health behaviors, and nutritional status. Public Health Rep 1989, 104:350-360.

21. Salive ME, Satterfield S, Ostfeld AM, Wallace RB, Havlik RJ: Disability and cognitive impairment are risk factors for pneumonia-related mortality in older adults. Public Health Rep 1993, 108:314-322.

22. Lange P, Vestbo J, Nyboe J: Risk factors for death and hospitalization from pneumonia. A prospective study of a general population. Eur Respir J 1995, 8:1694-1698.

23. Inoue $Y$, Koizumi A, Wada $Y$, Iso H, Watanabe $Y$, Date $C$, Yamamoto A, Kikuchi S, Inaba $Y$, Toyoshima H, Tamakoshi A: Risk and protective factors related to mortality from pneumonia among middleaged and elderly community residents: the JACC study. J Epidemiol 2007, 17:194-202.

24. Takata Y, Ansai T, Soh I, Akifusa S, Sonoki K, Fujisawa K, Awano S, Kagiyama S, Hamasaki T, Nakamichi I, Yoshida A, Takehara T: Association between body mass index and mortality in an 80-year-old population. $J$ Am Geriatr Soc 2007, 55:913-917.

25. Corrales-Medina VF, Valayam J, Serpa JA, Rueda AM, Musher DM: The obesity paradox in community-acquired bacterial pneumonia. Int J Infect Dis 2011, 15:e54-e57.

26. King P, Mortensen EM, Bollinger M, Restrepo MI, Copeland LA, Pugh MJ, Nakashima B, Anzueto A, Hitchcock NP: Impact of obesity on outcomes for patients hospitalised with pneumonia. Eur Respir J 2013, 41:929-934.

27. Kahlon S, Eurich DT, Padwal RS, Malhotra A, Minhas-Sandhu JK, Marrie TJ, Majumdar SR: Obesity and outcomes in patients hospitalized with pneumonia. Clin Microbiol Infect 2013, 19:709-716.

28. Singanayagam A, Singanayagam A, Chalmers JD: Obesity is associated with improved survival in community-acquired pneumonia. Eur Respir $J$ 2013, 42:180-187.
29. Stroup DF, Berlin JA, Morton SC, Olkin I, Williamson GD, Rennie D, Moher D, Becker BJ, Sipe TA, Thacker SB: Meta-analysis of observational studies in epidemiology: a proposal for reporting. Meta-analysis Of Observational Studies in Epidemiology (MOOSE) group. JAMA 2000, 283:2008-2012.

30. Wells GA, Shea B, O'Connell D, Peterson J, Welch V, Losos M, Tugwell P: The Newcastle-Ottawa Scale (NOS) for assessing the quality of nonrandomised studies in meta-analyses. Available at: http://www.ohri.ca/programs/ clinical_epidemiology/oxford.asp. (9 February 2014, date last accessed).

31. Greenland S, Longnecker MP: Methods for trend estimation from summarized dose-response data, with applications to meta-analysis. Am J Epidemiol 1992, 135:1301-1309.

32. Orsini N, Greenland S: A procedure to tabulate and plot results after flexible modeling of a quantitative covariate. Stata J 2011, 11:1-29.

33. White IR: Multivariate random-effects meta-analysis. Stata J 2009, 9:40-56.

34. Orsini N, Li R, Wolk A, Khudyakov P, Spiegelman D: Meta-analysis for linear and nonlinear dose-response relations: examples, an evaluation of approximations, and software. Am J Epidemiol 2012, 175:66-73.

35. Jee SH, Sull JW, Park J, Lee SY, Ohrr H, Guallar E, Samet JM: Body-mass index and mortality in Korean men and women. N Engl J Med 2006, 355:779-787.

36. Phung DT, Wang Z, Rutherford S, Huang C, Chu C: Body mass index and risk of pneumonia: a systematic review and meta-analysis. Obes Rev 2013, 14:839-857.

37. Lagergren J: Influence of obesity on the risk of esophageal disorders. Nat Rev Gastroenterol Hepatol 2011, 8:340-347.

38. Almirall J, Bolíbar I, Serra-Prat M, Roig J, Hospital I, Carandell E, Agustí M, Ayuso P, Estela A, Torres A, Community-Acquired Pneumonia in Catalan Countries (PACAP) Study Group: New evidence of risk factors for community-acquired pneumonia: a population-based study. Eur Respir $\rfloor$ 2008, 31:1274-1284.

39. Kornum JB, Thomsen RW, Riis A, Lervang HH, Schønheyder HC, Sørensen HT: Diabetes, glycemic control, and risk of hospitalization with pneumonia:a population-based case-control study. Diabetes Care 2008, 31:1541-1545

40. Vimaleswaran KS, Berry DJ, Lu C, Tikkanen E, Pilz S, Hiraki LT, Cooper JD, Dastani Z, Li R, Houston DK, Wood AR, Michaëlsson K, Vandenput L, Zgaga L, Yerges-Armstrong LM, McCarthy MI, Dupuis J, Kaakinen M, Kleber ME, Jameson K, Arden N, Raitakari O, Viikari J, Lohman KK, Ferrucci L, Melhus H, Ingelsson $E$, Byberg L, Lind L, Lorentzon M, et al: Causal relationship between obesity and vitamin D status: bi-directional Mendelian randomization analysis of multiple cohorts. PLOS Med 2013, 10:e1001383.

41. Aregbesola A, Voutilainen S, Nurmi T, Virtanen JK, Ronkainen K, Tuomainen TP: Serum 25-hydroxyvitamin D3 and the risk of pneumonia in an ageing general population. J Epidemiol Community Health 2013, 67:533-536.

42. Mancuso P: Obesity and respiratory infections: does excess adiposity weigh down host defense? Pulm Pharmacol Ther 2013, 26:412-419.

43. Ozata M, Ozdemir IC, Licinio J: Human leptin deficiency caused by a missense mutation: multiple endocrine defects, decreased sympathetic tone, and immune system dysfunction indicate new targets for leptin action, greater central than peripheral resistance to the effects of leptin, and spontaneous correction of leptin-mediated defects. J Clin Endocrinol Metab 1999, 84:3686-3695.

44. Myers MG Jr, Leibel RL, Seeley RJ, Schwartz MW: Obesity and leptin resistance: distinguishing cause from effect. Trends Endocrinol Metab 2010, 21:643-651.

45. Goel K, Lopez-Jimenez F, De Schutter A, Coutinho T, Lavie CJ: Obesity paradox in different populations: evidence and controversies. Future Cardiol 2014, 10:81-91

46. Puren AJ, Feldman C, Savage N, Becker PJ, Smith C: Patterns of cytokine expression in community-acquired pneumonia. Chest 1995, 107:1342-1349.

47. Mohamed-Ali V, Goodrick S, Bulmer K, Holly JM, Yudkin JS, Coppack SW: Production of soluble tumor necrosis factor receptors by human subcutaneous adipose tissue in vivo. Am J Physiol 1999, 277:E971-E975.

48. van de Garde EM, Oosterheert JJ, Bonten M, Kaplan RC, Leufkens HG: International classification of diseases codes showed modest sensitivity for detecting community-acquired pneumonia. J Clin Epidemiol 2007, 60:834-838.

doi:10.1186/1741-7015-12-61

Cite this article as: Nie et al:: Obesity survival paradox in pneumonia: a meta-analysis. BMC Medicine 2014 12:61 